\title{
PROF. DR. NEVZAT ÖZKAN'IN ADAM VAR ÂLEMDEN ÖTE ADLI ESERİ ÜZERINE
}

\section{Harun SAHİN*}

\section{1- Prof. Dr. Nevzat Özkan'ın Hayatı ve Eserleri ${ }^{1}$}

1961 yılında Yozgat'a bağlı Büyükkışla kasabasında doğdu. İlk ve ortaokulu doğduğu yerde, liseyi Kayseri Lisesinde, yükseköğrenimini Atatürk Üniversitesi Kâzım Karabekir Yüksek Öğretmen Okulunda okudu. 1982-1992 yılları arasında değişik illerde Millî Eğitim Bakanlığına bağlı okullarda Türk dili ve edebiyatı öğretmeni olarak çalıştı 1992 yılından beri Erciyes Üniversitesi Fen-Edebiyat Fakültesi Türk Dili ve Edebiyatı Bölümünde görev yapmaktadır.

1988 y1lında Erciyes Üniversitesi Sosyal Bilimler Enstitüsünde başladığı yüksek lisans eğitimini Yarkend $A \breve{g} z ı$ adlı teziyle, 1990 yılında aynı üniversitede başladığı doktora eğitimini ise Gagavuz Türkçesi Grameri adlı doktora teziyle tamamladı. 1994 y1lında yardımcı doçent, 1997 y1lında doçent oldu. 2003 yılında profesörlüğe atandı.

İlk yazıları Erciyes dergisinde çıktı. Daha sonra Türk Dili, Türk Edebiyatı, E.Ü. Sosyal Bilimler Enstitüsü Dergisi başta olmak üzere değişik aktüel ve akademik dergilerde yazıları yayımlandı. Millî ve milletlerarası kongrelere bildiri ile katıldı. 2000-2001 öğretim yılının bahar döneminde TİKA'nın desteğiyle Moldova'ya bağlı Gagavuz Özerk Bölgesi'nde bulunan Komrat Devlet Üniversitesinde konuk öğretim üyesi olarak çalıştı. 2015 yılında Yeni Ufuklar Derneğinin Türk Kültürüne Hizmet Ödülüne layık görülen Prof. Dr. Nevzat ÖZKAN evli ve üç çocuk babasıdır.

Yurt içi ve yurt dışı hakemli dergilerde yayımlanmış 11 makalesi, çeşitli tarih, kültür ve edebiyat dergilerinde yayımlanmış 83 deneme ve makalesi, 9 ansiklopedi konu yazarlığı, 20 sunulmuş ve yayımlanmış bildirisi, ulusal ve uluslararası toplantılarda 48 sunulmuş bildirisi ve yayımlanmış 9 kitabı bulunan Prof. Dr. Nevzat ÖZKAN'ın kitapları şunlardır: Gagavuz Türkçesi Grameri, Türk Dünyası Nüfus Sosyal Yapı Dil Edebiyat, Aziz Mahmut Hüdâyî Arapça ve Türkçe Tarîkatnâme, Ahmet Cevdet Paşa-Fuat Paşa, Kavâ'id-i Osmâniyye, Ahmet Cevdet Paşa, Medhal-i Kavâ'id, Türk Dilinin Yurtlarl, Gagavuz Destanlarl, Azîz Mahmûd Hüdâŷ̂ Tarîkatnâme Giriş-İnceleme-Metin-Dizin, Adam Var Âlemden Öte.

\footnotetext{
* Müfettiş; Yükseköğretim Kurulu Başkanlığı, harunsahin75@gmail.com.

${ }^{1}$ Prof. Dr. Nevzat ÖZKAN'ın Adam Var Âlemden Öte adlı kitabında yer alan yazarın öz geçmişi ile ilgili bilgilerden hareketle hazırlanmıştır.
} 


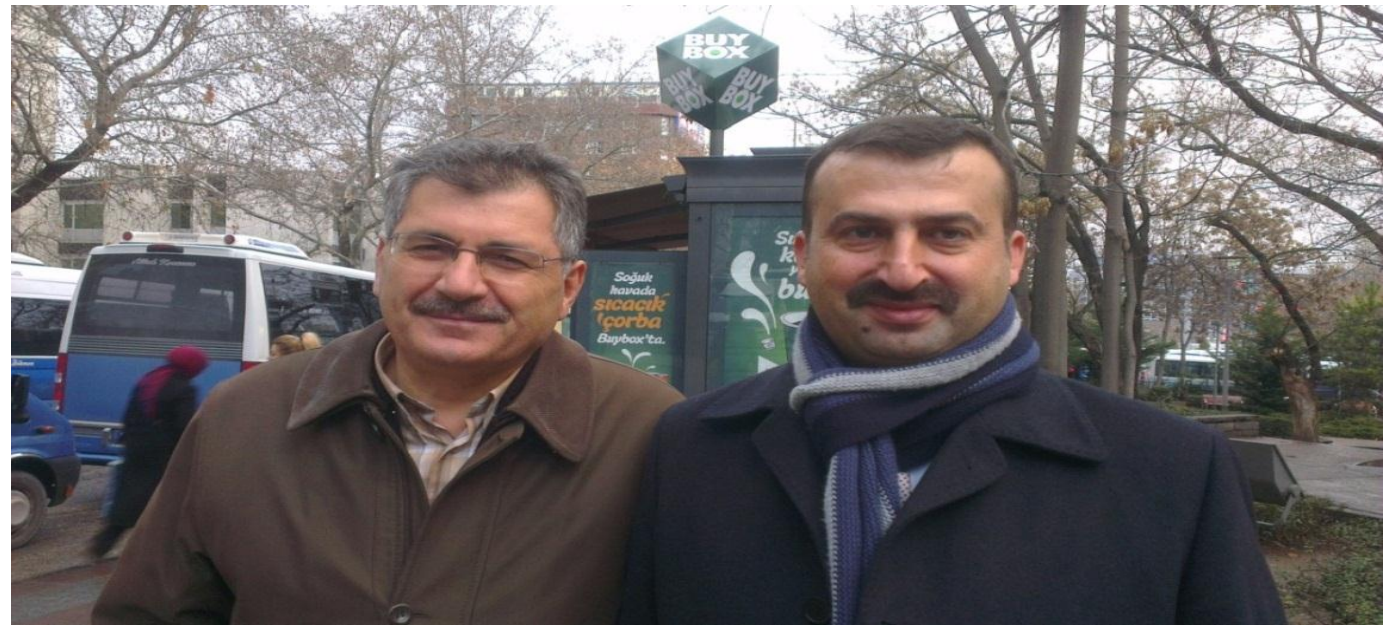

Foto 1: Prof. Dr. Nevzat ÖZKAN ile

\section{2- Prof. Dr. Nevzat Özkan'ın Adam Var Âlemden Öte adlı eseri:}

Prof. Dr. Nevzat ÖZKAN tarafindan yazılan ve deneme niteliğinde olan Adam var Âlemden Öte adlı eser, her biri bağımsız birer deneme olarak değerlendirilecek "Ön söz" dâhil 25 bölümden ve 192 sayfadan oluşmaktadır: “Ön söz” (s. 9-13), "Gönül Adamı” (s. 15-20), "Ali(ye)" (s. 21-29), "Baba Adam" (s. 30-34), "Bilim Adamı" (s. 35-40), "Dava Adamı" (s. 4149), "İman Adamı" (s.50-57), "Ruh Adam" (s. 58-68), "Adını Kaderine Yazan Adam” (s. 6977), "Erdemi Galip Kılmaya Çalışan Adam” (s.78-87), “Asker Adam” (s. 88-95), "Devlet Adamı" (s. 96- 103), "Fikir Adamı" (s. 104-109), "Halk Adamı" (s. 110-116), “Toprağın Sesiyle Konuşan Adam" (s. 117-124), "Hizmet Adamı" (s.125-129), "İş Adamı” (s.130-134), "Kültür Adamı" (s. 135-141), "Eğitim Adamı" (s. 142-153), "Yanlışı Söylemekten Geri Durmayan Adam" (s. 154-160), "Medeniyetimizi Şiirleştiren Adam” (s. 161-165), "Tarihi Destanlaştıran Adam" (s. 166-171), "Mücadele Adamı" (s. 172-187), "Yurdunu Kaybeden Adam” (s. 178 -186), “Adam ile Kadının Hikâyesi” (s. 187- 192).

Kitabın “Ön söz” (s. 9-13), bölümünde her şeyin günlük yaşanmasından, gündemin sürekli değişmesinden, modanın bütün hayatımıza hâkim olmasından şu şekilde şikâyet ediyor:

Günlük yaşayan geniş toplum kesimleri, çoğu zaman popüler veya meşhur olanla doğru ve iyi olanı birbirine karıştırıyor. Tanınır olan bazen iyi, doğru ve yararlı olanin önüne geçiyor. Göz önünde olan vitrin adamlarl, köşsesine çekilip işiyle gücüyle uğraşan gizli kahramanlardan daha çok rağbet görüyor (s. 9).

Ancak bütün bu yıkıcı akıcılığın içinde kalıcı, değişmeyen değerlerinde bulunduğu hatırlat1lyor: 
Unutmayalım, içinde yaşadığımız âlemde ne değişirse değişsin, ne kadar değişirse değisssin, hâlâ değişmeyen ve asla değişmeyecek olan çok önemli şeyler var.

Sü̈kürler olsun ki hâlâ insanız ve pek çoğumuz hâlâ iyi insanlar, doğru dürüst adamlar olmaya çalışlyoruz. Çevremizdeki insanların bazıları duruma göre çok çabuk değişse de insanî değerler ve ölçüler öyle kolayca değişmiyor (s. 10).

Kitapta, “Ön söz”ü takip eden 24 bölüm şöyle kurgulanmıştır: bir kavram ve o kavramın uyandırdığı tedailer üzerine genişçe bir düşünce beyanında bulunulduktan sonra, o kavrama numune-i imtisal teşkil edecek bir kişinin hayatından, bahse konu kavram işareti ile örnek kişinin örtüşen hususiyetlerinden bahsedilecek şekilde kurgulanmıştır.

"Gönül Adamı" (s. 15-20) bölümünde kelimeler, deyimler, atasözleri vasıtasıyla dil ve düşüncenin ufuklarında bir gezinti yapıp 13. asırda Anadolu'nun içine düştüğü girdabın anlatılmasından sonra Yunus Emre'den “insanların umutsuzluğa ve çaresizliğe düştügü bir zamanda, onları sabra, sükûnete, yık1lan mülkü imar ve inşa etmeye çalışan Yunus'un sesi yankılandı" (s. 20) şeklinde söz edilmiştir.

“Ali(ye)” (s. 21-29) bölümü, genel olarak "Alilerin dünyasında Aliyelerin parantez içine alınmış, yok sayılmış kimliklerini ve haklarını" (s. 21), erkek egemenliğine dayalı dünyadaki kadınları, özelde ise Ahmet Cevdet Paşa'nın kızı Fatma Aliye’yi konu edinmiştir. Yazar bu bölümde Fatma Ali(ye)'nin entelektüel kimliğinden, yazarlılığından, mücadeleyle geçen hayatından söz etmekle birlikte onun asıl ıstırabını şöyle anlatmıştır:

Çocukları üzerinde titreyen şefkat dolu bir anne olmasina rağmen büyük kızı Hatice, beyin hasarına sebep olan bir kaza geçirdi. Diğer kızları Ayşe ve Nimet aile hayatında sıkıntılar yaşadı. Bütün bu sıkıntıları göğüsleyebilirdi belki. Kızı İsmet'in lise yıllarında Katolik Hristiyanlığ benimsemesi ve rahibe olarak kendini adaması tüm dünyasinı altüst etti (s. 28).

"Baba Adam" (s. 30-34) bölümünde, toplumda baba kelimesinin kazandığı müspet anlam hatırlatılmış ve "hiçbir şeyin benzerinin, aslının yerini tutmadığı gibi hiçbir baba adam da bizim adamlığımızı borçlu olduğumuz babamızın yerini tutmaz" (s. 31) cümlesiyle yazar, hususiyle kendi rahmetli babasını, umumi olarak herkesin eli öpülesi babasını konu edinmiştir.

Ya o önemli kararlar arifesindeki telaş, "ne olacak bu çocuğun istikbali!” heyecanı, sizin için sizden daha fazla kaygllanan o baba yüreği, sizinle dolu ve sizin için titrediğini bildiğiniz o sıcacık gönül, sizin için sizden daha çok çalışan o bükülmez bilek (s. 32). 
Baba Adam bölümünün son cümlesi yaşadığımız ve yaşlanmakta olduğumuz dünyadaki mesleğimizi ve mirasımızı gözden geçirmemiz gerektiğini bize telkin ediyor: "Mesleği babalık, mirasi adamlık" (s. 34).

"Bilim Adamı" (s. 35-40) bölümü, bilim ve dil arasındaki ilişkiyi, istisnaları olsa da kimi bilim adamlarının Türkçeye yaptıkları haksızlıkları ve millet olarak bilime olan mesafeli duruşumuzu konu alır. Prof. Dr. Nevzat ÖZKAN'a göre bahsi geçen istisnai bilim adamlarından olan ve adına bilim denen "kutlu uğraşıya bir ömür vermiş" (s. 39), "Öğrencilerinin Türkolojinin Dede Korkut”u adını verdiği, gönlünün aklığı saçlarına vurmuş bu bilge..." Prof. Dr. Tuncer GÜLENSOY'dur.

“Adam olanın davası da olur" (s. 41) cümlesiyle başlayan "Dava Adamı" (s. 41-49) bölümü, dava adamlarının yaşadığı zorlukları ve bir başkası için, vatan için, millet için fedakârlıkta bulunmanın eşsiz hazzını bize sunar. Davasında sabitkadem olamayanların durumu ise şöyle açılanır:

Daha kötüsü en kutsal değerlerle donanmış bazı dava adamlarl, hayatın dayatmaları karşısında fazla direnememiş ve bir zamanlar toz konduramadıkları davalarını, başkalarının mal mülk davasıyla, makam mansip davasiyla takas etmek zorunda kalmışlardır (s. 42).

Bu bölümde ayrıca, "1917 yılında İngiliz işgali altında bulunan Lefkoşa'da dünyaya gelen" (s. 46) ve 1997 yılının nisan ayında ebediyete uğurladığımız Alparslan TÜRKEŞ dava adamı olarak örnek gösterilmiştir.

“İman Adamı" (s. 50-57) bölümünde iman, mümin, amentü ve bu kavramların samimiyet ile olan ilişkisi üzerine düşünceler serdedilir. İşin içine iman ve samimiyet girince bazen sessizce, çoğu zaman da davul zurna ile münafiklar gelip başköşeye oturuverirler:

Münafĭ̆ın doğru yapmak veya yanlışa düşmek gibi bir endişesi yoktur, kendi doğrusunu hayatın her alanında yaşar ve yaşatır. Sadece anlık çıkarlar ve o çıkarlar için her şeyi göze almış doymaz bir iştiha ve tükenmez bir ihtirası vardır (s. 51).

Göğsünün en müstesna yerinde, iman ile ihlası kalp etmiş hakiki iman erleri ise "ait oldukları toplumların övünç kaynağıdır. Yeni yetişen nesillere onlar örnek gösterilir. Onların mücadeleleri efsaneleştirilir. Geride bıraktıkları eserler devletin ve toplumun ortak koruması altındadır” (s. 52). Tıpkı "zulmü alkışlamayan zalimi asla sevemeyen” diyen Mehmet Akif gibi. 
58-68. sayfalar arasındaki bölüme, kahramanı ve olayları ile Hüseyin Nihal ATSIZ'ın hayatını yansıtan o meşhur romanın ismi başlık yapılmıştır. "Ruh Adam" adını taşıyan bu bölümde, eski Türk inanışındaki "yer-su” kavramından hareketle, ruh-beden ilişkisi ve millî ruh merkezli geniş bir değerlendirme yapılır. Millî ruhu kaybedildiğinde Türk milletinin içine düştüğü müşkül durum, tarihten çağrışımlar yapılarak anlatılmaya çalışılır. Bahsi geçen bu ruha sahip çıkıldığında ise neler yapılabileceği şu şekilde ifade edilir:

Kuzey Buz Denizi'nde donmadık, Orta Asya bozkırlarında yanmadık. Dağları aştık, yolları geçtik. Geceleyin ayı yıldızı rehber kıldık, gündüzleri güneşi takip ettik, hep yeni ufuklara koștuk. Bir ucumuz Çin Seddi'nde öbür ucumuz Roma kapısında efsane olduk, destan yazdlk (s. 60).

“Adını Kaderine Yazan Adam” (s. 69-77) bölümünde, isimlerin insan üzerindeki etkisinden, isim verme geleneğinden, ismiyle müsemma olmak ile isminin ağırlığını taşıyamamak deyimlerinden söz edilir. Bir de "Kaderine razı samimi bir müminin teslimiyetiyle çalışmalarını aralıksız sürdüren Turan'ın ak saçlı bilgesi” (s. 77) Turan YAZGAN'ın ismiyle nasıl müsemma olduğu, adıyla kaderinin nasıl benzeştiği konu edinmiştir.

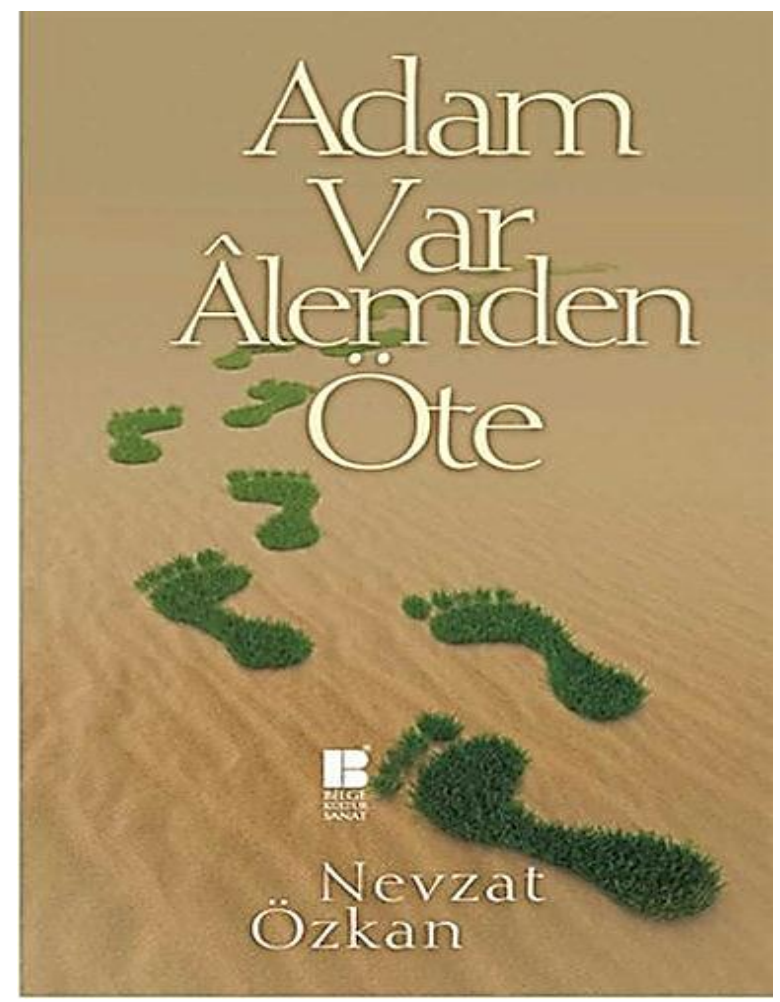

Foto 2: Adam Var Âlemden Öte adlı eserin kapak görüntüsü 
"Erdemi Galip Kılmaya Çalışan Adam” (s. 78-87) bölümünde okuyucuyu, diğerkâmlık, erdem, ahlak, vefa kelimeleri etrafında bir düşünce turuna çıkarır. Bu düşünce seyahatinin son durağı Galip ERDEM'dir. Bazılarına göre "Kendini Unutan Adam" bazılarına göre de "Rütbesiz Mareşal” yazara göre ise "Erdemi Galip Kılmaya Çalışan Adam”: Galip ERDEM.

“Asker Adam" (s. 88-95) bölümünde askerlik ile adamlık kelimelerinin bağlantıs1 kurularak ordu millet olmanın tarih sürecindeki yeri okuyucuya sunulmuştur. Peki, askerlik, asker millet olmak bize ne öğretir: Yazara göre askerlik, “... ayrı düşünsek de toplu hareket etmeyi, daha önemlisi aynı hedefe yönelmeyi, aynı yere bakmayı, hep bir ağızdan aynı şeyleri haykırmayı öğretir: Her... Türk... Asker... Doğar!’(s. 89).

Her Türk asker doğar ama bazen askerî kimliklerle siyasi kimlikler birbirine karışır. Sağdan soldan ölümler, zulümler hayata hâkim olur. Öte yandan askerlik ile siyaseti birbirine karıştırmayan bu iki kavramı adamlık ile taçlandıran birileri de var bu bölümde: Türkiye Cumhuriyeti’nin ilk Genelkurmay Başkanı Fevzi ÇAKMAK.

"Devlet Adamı” (s. 96-103) bölümü güç, talih, düzen, hükümranlık, devlet, şefkat, merhamet ve baba kelimeleri etrafında şekillenerek Mustafa Kemal Paşa'nın devlet adamlığı ile hitam bulmuştur.

"Fikir Adamı" (s. 104-109) bölümünde, ak1l ve fikir sahibi olmak ile fikir sahibi olanların çektiği çileler anlatılır. En mübarek çilenin fikir çilesi olduğu söylenerek Ziya GÖKALP'in fikir adamlığından söz edilmiştir.

"Halk Adamı" (s. 110-116): "Hepimiz aslında aynı gök kubbenin altında, aynı yer kürenin üstünde birbirine benzer hayatlar" (s. 110) yaşasak da "asalet ve sinıf üstünlügüne dayalı düşüncelere yabancı toplum hayatımızda en sıradan insanlar, sadece talihleri ve becerileri ile devlet ve millet nezdinde en yüksek makamlara" (s.112) ulaşabilseler de okuyup yazmakla, gezip görmekle, parayla pulla sahip olunamayacak makamlar vardır. Halk ile uyumlu, halka faydalı, halkın haliyle hâllenen halk adamlığı böyle bir makamdır. Yazar, eserinin bu bölümünde halk adamı olarak Kayserili Emir KALKAN'ı anlatmıştır.

“Toprağın Sesiyle Konuşan Adam” (s. 117-124) bölümü, toprağı vatan eylemek için verilen uğraşları, mülk davasında içine düştüğümüz yanlışları, Türk mülkü üzerinde Türkçenin boynu bükük günlerini ve yeniden devletin, milletin, sevginin, şefkatin, sohbetin dili oluşunu ve kutlu yenilenmeye bozkırın öğretmeni, müfettişi İmdat AVŞAR'ın bu sürece katkılarını anlatır. 
"Hizmet Adamı" (s. 125-129) bölümü beni 13 sene öncesine götürdü. Erciyes Üniversitesi Sosyal Bilimler Enstitüsünde yüksek lisans öğrencisi idim. Bir salı günü hocamız Prof. Dr. Nevzat ÖZKAN bize Eski Uygur Türkçesi anlatıyordu. İçeriye bir adam girdi. Bize Erciyes dergisini getirmişti. O gün hizmet adamını tanıdım: Nevzat TÜRKTEN. Kitabın bu bölümünde anlatılanları veya benzerlerini o gün dinlemiştim. Toplum olarak pek kıymetini bilmediğimiz bu insanlar hakkında kitap şöyle diyor:

Makam mansip işlerine pek gelemezler. Üstlenecekleri önemli makam ve görevlerin kendilerine sağlayacağı imkânlardan çok, altına girecekleri manevi sorumlulukları hesap ettikleri için çoğu kez işleri, daha kıvrak endamlı iş bitirici adamlara kaptırırlar. Onun için de dostları ve yakın çevreleri, onları, hep çok çalışı uğraşıp da bir türlü bir baltaya sap olamayanlar sinıfina dâhil ederler" (s. 127).

“İş Adamı” (s. 130-134) bölümünde iş, insan, hayat, eğitim ve halk kelimeleri ekseninde bir düşünce turunun ardından Sakıp SABANCI anlatılmıştır.

"Kültür Adamı" (s. 135-141): Kültür ve kardeşleri olan ümran, uygarlık, irfan kelimeleri hep bize Cemil MERIÇ̧’i hatırlatır: "Ümrandan Uygarlığa”, "Kültürden İrfana” isimli eserlerde olduğu gibi.

Kültür adamlığl, insanin kendini tanıması ve anlamasıyla başlayan, tüm hayatı ve insanlığ kavramasıyla şekillenen, ön yargılardan uzak sağlam bir bilgi birikimine ve düşünce mekanizmasina ulaşmakla sonuçlanan uzun ve sıkıntılı bir yolculuktur.

Felaketlerle dolu bir zamanda ve düşman işgali ile çiğnenen bir zeminde hayata başlayan Hüseyin Cemil MERIÇ, işte böyle kutlu bir yolun yolcusu olarak yaşadı (s. 139).

"Eğitim Adamı" (s. 142-153) bölümünde, eğitimin önemi ve tarihimizdeki yeri üzerine düşünceler paylaşıldıktan sonra yazarın Kayseri Lisesinden edebiyat öğretmeni olan Mustafa ÖZTÜRK'ün eğitimciliği anlatılmıştır.

"Yanlış1 Söylemekten Geri Durmayan Adam" (s. 154-160) bölümü, tenkit konulu bir denemedir. Nasıl bir tenkit olmalı? Sorusuna şöyle cevap verilmiştir: "Zihinlerde gerçeğin şimşeğini patlatacak bir fikir çarpışmasına yol açmayan bir tenkit yersiz, böyle bir beceriye veya yeteneğe sahip olmayan münekkit ise yeteneksizdir” (s. 158). Yazının son bölümleri Orhan Şaik GÖKYAY ile süslenmiş, onun tenkidi yazarın kaleminden şöyle tarif edilmiştir: "Hep doğruyu arad1, hep mükemmeli istedi. Yanlışlar ve hatalarla uğraşmaktan geri durmadı. Haddini aşıp 
bilmediği konular üzerine ahkâm kesenleri de Destursuz Bağa Girenler diyerek yerden yere vurdu. Niyeti, insanları rencide etmek değildi. Gördüğü güzel işlerin sahiplerini kutlamaktan çekinmedi” (s. 159).

"Medeniyetimizi Şiirleştiren Adam" (s. 161-165) bölümü, şiirin ve şuurun birbiriyle ve medeniyetle olan ilişkisi ile medeniyetimizi şiirine konu yapan şairler hakkında yazılmış bir denemedir. Örneğin "Köklerimizi muhteşem medeniyetimize ve mazimize uzanan bir âtiyi kurmaya çalıştığımız bir çağda, bize ait bütün güzellikleri bir bayram sabahında Kendi Gök Kubbemiz altında Süleymaniye'de buluşturan Yahya Kemal BEYATLI” (s. 164) medeniyetimizin şiirleştirilmesinde önemli bir yere sahiptir.

“Tarihi Destanlaştıran Adam” (s. 166-171) bölümünde destan, tarih, roman kelimeleri etrafında "Çin'den Avrupa ortalarına, Afrika'nın kavurucu çöllerinden Sibirya buzullarına kadar uzanan topraklarda bu kadar sık ve çok yolculuk etmiş, devlet kurmuş başka ülkelerin ve milletlerin kaderi üzerinde etkili olmuş" (s. 167) olan Türk milletinin tarihini edebiyatına konu yapamayışının 1stırabı duyulur. Yazara göre bu 1stırabı duyan ve ömrünü tarihi destanlaştırmaya adamış, pek de kıymetini bilemediğimiz birisi de Mustafa Necati SEPETÇİOĞLU'dur.

“Mücadele Adamı" (s. 172-187) bölümünde hırs, açgözlülük ve zulüm kelimeleri ile millî mücadele, millet olma mücadelesi ve Kıbrıs davası kelime guruplarınca sınırları çizilen bir çerçeve kurulur. Bu çerçevenin ortasında da Kıbrıs mücadelesinin sembol ismi rahmetli Rauf DENKTAŞ'ın resmi vardır.

"Yurdunu Kaybeden Adam" (s. 178 -186): Yurdunu Kaybeden Adamı tanıyoruz. Aşina olduğu bir adam o. Kırım Türklüğünün yurdunu kaybetmesinin acısını duyurdu okuyucularına. Hatırlayalım: "Bir gecede tümünü trenlere bindirerek Sibirya'ya, Özbekistan'a ve Urallar'a sürdüler. Sürgüne gönderilenlerin yarısı yollarda sadece yurtlarını değil, hayatlarını da kaybettiler. Kırım'da sadece Türkler değil, Türklüğe dair her ne varsa yok edildi” (s. 182).

Yazar Cengiz DAĞCI, bu acıları Yurdunu Kaybeden Adam, Onlar da İnsandl, Korkunç Ylllar $v d$. eserlerine konu edindi.

“Adam ile Kadının Hikâyesi” (s. 187- 192) bölümü kitabın son bölümüdür. Bu bölümde $H z$. Adem ile Havva'dan modern çağa kadar kadın ve erkeğin üstlendiği roller ve bu rollerin birbirine girmesi, insan türünün yaşadığı bir trajedi ve tehdit olarak dikkatlere sunulmuştur:

Kadın sosyal hayatta üstlendiği yeni sorumluluklarla, kurucusu ve koruyucusu olduğu aile kurumu içinde üstlendiği rollerden uzaklaşmak veya sosyal hayatta 
üstlendiği yeni rollerle kadınlık vasfinın ona yüklediği roller arasında seçim yapmak zorunda kalmıştır. Bu durum kadını, hem kadın olmak hem de erkeklerle, onların koyduğu kurallarla yarışmak gibi çok zor ve sıkıntılı bir noktaya taşımış̧tır (s. 191).

Prof. Dr. Nevzat ÖZKAN bir Türk dili hocasıdır. Çalışmalarıyla Türklük bilimine önemli katılar sağlamıştır. Ancak, son kitabı "Adam var Âlemden Öte" bilimsel bir kitap olmayıp bilimsel çalışmalara konu olabilecek bir denemedir.

Yazarın, günlük hayatındaki sadeliği, samimiyeti, candanlığı kitabın her sayfasında hissedilmektedir. Onun kitabını okurken eskilerin "üslûb-1 beyan aynıyla insan" sözüne bir kez daha hak veririz.

Seçtiği konularla okuyucuyu ufuktan ufka koşturan, bu koşma sırasında hiç yorgunluk hissi vermeyen sade, samimi, akıcı üsluba sahip eserinden dolayı Prof. Dr. Nevzat ÖZKAN'1 tebrik eder, yeni eserlerini edebiyatımıza kazandırmasını temenni ederim. 